\title{
LER - LESÃO POR ESFORÇOS REPETITIVOS \\ UM CONCEITO FALHO E PREJUDICIAL
}

\author{
JOSÉ TEOTONIO DE OLIVEIRA*
}

\begin{abstract}
RESUMO - O conceito de que movimentos repetitivos ou posturas prolongadas causam lesões não tem suporte científico. Os sintomas dolorosos e sensitivos apresentados pelos pacientes são melhor explicados como um fenômeno psicológico e psicossocial, como insatisfação e desadaptação no trabalho e desejo de obter benefícios. O conceito de lesões por esforços repetitivos é iatrogênico e de custo elevado para a sociedade, devendo ser abandonado.
\end{abstract}

PALAVRAS-CHAVE: lesão por esforços repetitivos, traumas cumulativos.

\section{RSI - Repetitive Strain Injury: a questionable and harmful concept}

ABSTRACT - The hypothesis that repetitive movements and postures cause musculoskeletal injury is not supported by scientific data. The sensory and pain symptoms are better explained as of psychological and psychosocial nature, such as job insatisfaction or disajustment, with financial gains objectives. The repetitive strain injury concept is iatrogenic and costly to society, and must be abandonned.

KEY WORDS: repetitive strain injury, cumulative trauma disorder.

LER - lesão por esforços repetitivos - é um diagnóstico feito em trabalhadores empregados (o fenômeno praticamente não acomete trabalhadores autônomos) apresentando-se com queixas dolorosas e sensitivas, de localização em determinadas regiões do corpo, de modo geral a mais utilizada nas suas funções e nas quais não são detectadas alterações ao exame físico. LER adquiriu nos últimos anos grande destaque, tanto na prática médica quanto nos meios de comunicação de massa, em que é apresentada como novo flagelo da humanidade.

O fenômeno LER começou na década de 70, primeiramente nos países mais ricos e tecnicamente desenvolvidos. Posteriormente difundiu-se para os setores mais desenvolvidos dos países em industrialização, como o Brasil. Com o passar do tempo, foi atingindo setores menos sofisticados da economia.

O conceito é muito atraente para a classe médica, pois oferece um diagnóstico simples de pacientes com sintomatologia complexa e intrigante. Também é atraente para os pacientes, pois atribui os sintomas à esfera física e não psicológica, a qual, de modo geral, não é bem aceita ${ }^{1,2}$. Além da satisfação psicológica de terem os sintomas atribuídos a uma lesão, os pacientes são ainda gratificados com pensões especiais e indenizações e assistência médica diferenciada. $\mathrm{O}$ conceito de LER é também atraente para os empregadores, pois permite que o peso dos trabalhadores mal adaptados seja transferido para o sistema previdenciário. O conceito de LER transformou o local de trabalho em um ambiente perigoso, para cuja solução implantou-se uma burocracia reguladora e fiscalizadora.

*Departamento de Neurologia e Psiquiatria da Universidade Federal de Minas Gerais (UFMG), Serviço de Neurologia e Neurocirurgia do Hospital das Clínicas da UFMG. Aceite: 14-dezembro-1998. 
A National Coalition on Ergonomics (NCE) estima que serão necessários US\$600 bilhões em 5 anos para as adaptações dos ambientes de trabalho nos Estados Unidos se forem aceitas as exigências da Occupational Safety and Health Administration (OSHA), atualmente em tramitação no congresso americano ${ }^{3}$.

\section{HISTÓRIA DO DESENVOLVIMENTO DO CONCEITO DE LER}

Nos tempos mais recentes, a atribuição de sintomas músculo-esqueléticos a determinado trabalho começou no Japão em 1958, em perfuradores de cartões, cujas queixas dolorosas regionais começaram a ser rotuladas inicialmente de tenossinovite e posteriormente de síndrome cervicobraquial, refletindo uma atenção maior às queixas cervicais, também presentes. A partir de 1973 estes sintomas passaram a serem denominados "distúrbio cervicobraquial ocupacional", sendo introduzido neste termo uma conotação causal ${ }^{4}$.

Na década de 80 ocorreu na Austrália uma epidemia de sintomas dolorosos na região cervicobraquial, que em alguns locais chegou a atingir $80 \%$ dos trabalhadores ${ }^{5}$. Estes sintomas passaram a ser denominados "repetitive strain injury" ("RSI"), que era um termo até então utilizado na literatura ortopédica para descrever lesões apresentadas por corredores de longa distância. Lesão por esforços repetitivos (LER) é a tradução de "repetitive strain injury". Esta nova denominação presume a presença de uma lesão e o mecanismo pelo qual ela ocorre.

Recentemente, ensaia-se o uso do termo "distúrbios osteomusculares relacionados ao trabalho" (DORT). Este é muito abrangente, dispensa a relação causal, não exige qualquer explicação quanto ao mecanismo de acometimento, sendo suficiente a relação com trabalho.

Um grande evento na história da LER ocorreu em 1986 quando após reunião de consenso, o National Institute of Occupational Safety and Health (NIOSH), nos Estados Unidos, emitiu a seguinte declaração: "Quando as exigências do trabalho ...repetidamente excedem a capacidade biomecânica do trabalhador, as atividades tornam-se indutoras de trauma. Portanto, traumatógenos são as fontes de lesões no local de trabalho que afetam o sistema músculo-esqueléticos". Com esta declaração o "distúrbio por traumas repetitivos" ("DTR"), tradução de "cumulative trauma disorder" ("CTD"), termo mais utilizado nos Estados Unidos, foi colocado na lista das preocupações nacionais. Funcionários de sindicatos e da segurança do trabalho, bem como a mídia, foram ágeis em avisar seus membros e o público em geral dos perigos potenciais do "DTR". O impacto econômico nas empresas foi dramático. Os prêmios dos seguros, nos Estados Unidos, que antes representavam 1 a $5 \%$ das folhas de pagamento, em alguns casos atingiram $30 \%$, afetando a competitividade das empresas ${ }^{6}$.

No Brasil, o conceito ergonômico foi rapidamente absorvido. Foi oficializado através da Portaria 40062/ 1987 e das "Normas Técnicas para a Perícia Médica do INSS" (NTPMINSS) de 1991, revistas em 1993 e recentemente em agosto de $1998^{7}$. Na elaboração das normas participaram sindicatos, empregadores, órgãos de classe, Ministérios do Trabalho, da Previdência Social e da Saúde, não sendo, portanto, normas puramente técnicas.

As NTPMINSS destacam várias patologias reumáticas, ortopédicas e neurológicas que acometem os tecidos moles dos membros superiores e passam ao largo do grande grupo de pacientes sem sinais físicos que suportem as queixas dolorosas. As NTPMINSS dão a impressão de que as queixas dolorosas são geralmente consequências de diversas patologias, para as quais estabelece critérios diagnósticos muito liberais. Relaciona as queixas e patologias ao trabalho e ignoram a ocorrência delas na população em geral. Estabelecem que a queixa de dor isolada, sem sinais clínicos de lesão, pode ser suficiente para o diagnóstico de LER, com todos os desdobramentos médicos e de benefícios sociais, desde que tenham um nexo com a atividade laboral. LER é definida como toda dor regional ocorrendo no trabalhador em uma atividade de risco. Os fatores do trabalho que podem provocar LER são abrangentes e universais: posturas inadequadas, carga estática, carga músculoesquelética, pressões locais sobre os tecidos, invariabilidade das tarefas, exigências cognitivas, fatores organizacionais e psicossociais ligados ao trabalho, grau de adequação do posto de trabalho, zona de atenção e visão, frio e vibrações ${ }^{7}$. Estes fatores podem ocorrer isoladamente ou em combinações. São considerados fatores de risco porque causam LER. A definição oficial de LER, que está colocada no plural é, pois, baseada em um raciocínio circular. As NTPMINSS abrem caminho para qualquer trabalhador com sintomas dolorosos regionais habilitar-se a um benefício.

O número de pessoas com queixas atribuídas a traumas repetitivos tem aumentado em todo o mundo industrializado ${ }^{8-10}$. As causas deste aumento são a disseminação do diagnóstico LER por uma mídia ávida por novidades médicas e interesses dos setores beneficiados, além da própria expansão e liberalidade do conceito. É difícil de acreditar que o aumento seja devido a piores condições de trabalho. 


\section{CAUSAS DOS SINTOMAS DOLOROSOS}

O termo LER produz a impressão de que os fatos são inequívocos e o diagnóstico muito claro. Na realidade, o termo é enganoso e o conceito de que esforços repetitivos provoquem lesões, que seriam responsáveis pelos sintomas, é polêmico ${ }^{11}$. Não há acordo a respeito da causa dos sintomas, a patologia não foi inequivocamente demonstrada e a literatura é falha e criticável ${ }^{6,12-14}$. As características clínicas são confusas e inespecíficas e não há método diagnóstico útil ${ }^{12,15}$.

Há duas correntes de opiniões opostas sobre a causa dos sintomas dolorosos ${ }^{16}$. A corrente de ergonomistas, lideradas por Armstrong e Silverstein, acredita que os sintomas são devidos a lesões verdadeiras, embora não ainda demonstradas, causadas por força, repetição, posturas anormais e vibrações. A outra corrente é liderada por Hadler nos Estados Unidos e por Ireland na Austrália e atribui os sintomas a fatores psicossociais e políticos.

Devido à ausência de alterações patológicas convincentes nas regiões dolorosas, os defensores do conceito ergonômico da LER têm atribuído a persistência dos sintomas dolorosos a distúrbios dos mecanismos de percepção e interpretação da dor localizados no corno posterior da medula e nos centros encefálicos ${ }^{17,18}$. Na verdade, isto equivale dizer que o mecanismo de persistência da dor é psicológico.

Alguns autores acham que a LER é um fenômeno social. Shorter ${ }^{1,19}$ iguala a epidemia de diagnóstico de LER a modismos diagnósticos de outras eras como "apendicite" no fim do século passado (desapareceu quando os cirurgiões passaram a operar alguns casos), "colite", "hipoglicemia", "brucelose". Ele atribui os sintomas a uma cultura e a uma mídia que encorajam as pessoas a considerar sintomas vagos e inespecíficos como evidência de doença real e a procurarem a ajuda de especialistas. A escolha (inconsciente) de sintomas sensitivos deve-se a serem eles difíceis de ser desmentidos pelos médicos. Até o carácter litigante da LER tem paralelo na história na figura da "síndrome das ferrovias" em que pessoas envolvidas em acidentes ferroviários e que não sofriam lesões graves desenvolviam sintomas dolorosos e mentais altamente incapacitantes, para os quais exigiam indenizações, com frequência vultuosas ${ }^{20}$.

A maioria dos autores nacionais defende o conceito ergonômico das LER, reconhecendo que elas (seguem o conceito de que são várias as LER) não podem ser explicadas pela metodologia médica ortodoxa. Atribuem a epidemia às relações e métodos de trabalho ${ }^{10,21,22}$, sendo o trabalhador visto não como uma pessoa que trabalha para adquirir seu sustento mas como uma vítima do sistema $^{10,21}$. Os autores descrevem várias patologias reumáticas, ortopédicas e neurológicas, transmitindo a impressão de que elas ocorrem com frequência nos pacientes com as queixas dolorosas e, como nas NTPMINSS, ignoram os aspectos psicológicos e psicossociais como causa, preferindo colocá-los como consequência. O diagnóstico é feito a partir do trabalho, não a partir do paciente.

\section{AVALIAÇÃO CLÍNICA DOS DISTÚRBIOS DOLOROSOS RELACIONADOS AO TRABALHO}

Os trabalhadores com queixas dolorosas devem ser avaliados pelo método clínico tradicional, no qual as atividades físicas, seja do trabalho ou do lazer, devem fazer parte da anamnese. $\mathrm{O}$ médico deve estar atento para os aspectos psicológicos que podem influenciar a percepção de dor. A dor que uma pessoa sente não é devida somente à lesão. Dor, de acordo com a definição da International Association for the Study of Pain, é uma experiência sensitiva e emocional desagradável associada com uma lesão atual ou potencial de um tecido. A dor é sempre subjetiva. Cada indivíduo aprende através da experiência o que isto significa realmente e quais ganhos secundários podem ser gerados. A dor, portanto, tem dois componentes: um físico, que pode ser real ou potencial (o paciente supõe que um evento pode ser fonte de dor) e um emocional, psíquico ${ }^{23}$. A falha em identificar os aspectos psicossociais, aqui incluídos benefícios como afastamento do trabalho e indenizações, pode deixar o médico perplexo com os fracassos dos tratamentos e intervenções. 
Os pacientes, de modo geral, não fornecem informações sobre o estado psicológico espontaneamente, devendo estas informações ser procuradas por iniciativa do médico. A maioria dos trabalhadores com queixas dolorosas não apresenta alterações físicas detectáveis pelos diversos métodos diagnósticos ${ }^{24,25}$.

Exceto pela cronicidade, os sintomas da denominada LER ocorrem com frequência na população em geral. Sintomas músculo-esqueléticos, como dor e fadiga, caracterizados por desconforto com o uso da região acometida, até mesmo com alguma restrição da amplitude de movimentos, são comuns em pessoas normais, independentemente do tipo de atividade, ocorrendo em donas-de-casa, atletas, estudantes, trabalhadores sedentários, embaladores de material ${ }^{13,26}$. Em um estudo epidemiológico, 36,7\% das pessoas relataram ter sofrido dor articular, 31,5\% dor lombar e $24,3 \%$ dor na perna ${ }^{27}$. A imensa maioria das pessoas tolera, suporta e supera estes problemas, considerando-os fatos da vida e os sintomas desaparecem espontaneamente.

A conduta de investigações excessivas e desnecessárias e a falha em tranquilizar o paciente quanto à natureza benigna dos sintomas, pode alarmar o paciente, reforçar a convicção da existência de uma doença e perpetuar um comportamento de doente ${ }^{5}$.

A supervalorização de sintomas comuns pelo médico, combinada ao excesso de intervenções é um fenômeno conhecido como medicalização (28). Esta pode contribuir significativamente para a amplificação e perpetuação do problema inicialmente simples. Mesmo intervenções aparentemente inofensivas, como o repouso, podem ter implicações importantes no modo como as pessoas percebem a doença ${ }^{29,30}$. A informação dada aos trabalhadores de que sintomas dolorosos relacionados a certas atividades são o prenúncio de uma lesão grave, progressiva e irreversível, além de falsa, tem potencial iatrogênico elevado, sendo um desserviço gigante ao paciente ${ }^{16,31}$. Esta informação terá grande impacto nas pessoas somatizadoras e nas impressionáveis. Ela agrada plenamente aos que pretendem conseguir privilégios e benefícios.

A informação de que há uma catástrofe à frente caso não sejam tomadas medidas imediatas dificulta a recuperação, que ocorre em razão de adaptação, tolerância a certo grau de desconforto e dor. A pessoa só se sentirá protegida na ausência de qualquer sintoma, o que nem sempre será possível. Assim inicia-se o processo de incapacidade, que pode atingir um estágio irreversível. Neste processo, o paciente tende a ampliar as queixas para convencer a si próprio e a quem o examina e concede o benefício, pois quanto mais lesão e quanto maior o tempo de incapacidade maiores são as chances de se obter os benefícios máximos ${ }^{32}$.

Frequentemente os trabalhadores envolvem-se em litígio, processo emocionalmente carregado e que pode ter consequências psicológicas dolorosas ${ }^{33}$. Nos casos litigiosos, a possibilidade de incapacidade permanente é grande ${ }^{32}$, pois o trabalhador passa a ser interessado na permanência dos sintomas, geralmente sob o incentivo e orientação de um advogado, sindicato ou colegas. Mesmo quando o caso é finalmente encerrado, os sintomas dolorosos podem persistir devido ao medo de que a cura possa ser interpretada como prova de que tudo não passou de uma fraude, tanto na perspectiva do paciente quanto das pessoas do seu meio social. A possibilidade de uma revisão médica no futuro com possível retirada do benefício também funciona como mecanismo de cronificação dos sintomas $^{34}$.

Os trabalhadores com queixas dolorosas crônicas sem patologia demonstrável respondem mal, de modo geral, às intervenções médicas ${ }^{24}$, ao contrário daqueles com patologia, sendo uma indicação de que o problema não é de natureza física. A perspectiva de uma aposentadoria ou indenização tem efeito negativo sobre recuperação, desencorajando os trabalhadores a retornarem ao trabalho após uma lesão, reforçando os sintomas ${ }^{35}$. 


\section{PROPOSTAS PARA O ABANDONO DO CONCEITO DE LER}

Autores e entidades médicas vêm propondo o abandono do conceito de LER por falta de suporte científico e pelo seu caráter iatrogênico ${ }^{1,13,34}$. Hadler ${ }^{13}$ acha que LER não é um evento clínico mas um fenômeno social, igualando LER a vários diagnósticos populares que recebem suporte da mídia para suas autenticidades, e que têm como finalidade evitar que os médicos designem certos sintomas como de origem psíquica.

Wright ${ }^{36}$ considera LER "uma má idéia, que é melhor ser esquecida” e Bell ${ }^{37}$, após análise da literatura, concluiu que LER caracteriza uma epidemia de lesão simulada, causada e propagada por médicos, ergonomistas e outros profissionais de saúde e de segurança do trabalho. Devido à observação de que sindicatos, organizações do trabalho, grupos de pressão e imprensa leiga ativamente difundem o conceito de LER, Cleland ${ }^{38}$ considerou LER um exemplo de iatrogênese social.

Várias sociedades médicas têm se posicionado contra o conceito de LER. Um relatório do Comitê de Lesões Industriais da Sociedade Americana de Cirurgia de Mão conclui: ..."não existe evidência suficiente na literatura médica para concluir que o trabalho é a única causa do chamado trauma cumulativo. Denominando erroneamente as queixas de um paciente, e equivocadamente relacionando-as queixas ao trabalho, é prejudicial" ${ }^{31,39,40}$. Segundo o relatório de um grupo de trabalho da British Orthopaedic Association, baseado em revisão da literatura, ...”'A terminologia usada nos trabalhos publicados sobre lesões por esforços repetitivos é altamente insatisfatória e deve ser descartada. Nenhuma condição deve ser diagnosticada como doença industrial a menos que possa ser definida patológica e clinicamente sem ambiguidades. No momento, as evidências de causa ocupacional são inconclusivas para diagnosticar quaisquer tipos de "LER"14.

\section{CONCLUSÃO}

Sintomas dolorosos e sensitivos mal definidos e mal localizados dos membros superiores e cintura escapular raramente são devidos à lesões estruturais ${ }^{24,25}$. Na maioria das vezes são fenômenos inerentes ao trabalho muscular. Não foi demonstrado até o presente que esforços repetitivos sejam responsáveis por lesões, sendo que o incipiente uso do termo "distúrbios osteomusculares relacionados ao trabalho-DORT” sinaliza o abandono desta hipótese.

O conceito de LER, além de não ter bases científicas, é iatrogênico, indutor de comportamento de doente. É um conceito que desvia as atenções para longe do problema real, provavelmente insatisfação no trabalho, problemas psicológicos pessoais, e até mesmo fraude ${ }^{15,41}$.

O conceito está levando à proposição de soluções inapropriadas e custosas que, combinadas com o grande número de pessoas em benefícios sociais, muito custam à sociedade. $\mathrm{O}$ maior drama, todavia, é a legião de incapacitados e o sofrimento que está produzindo.

\section{REFERÊNCIAS}

1. Shorter E. The borderland between neurology and history: conversion reactions. Neurol Clin 1995;13:229-239.

2. McWhinney IR, Epstein RM, Freeman. Ann Intern Med 1997;126:747-750.

3. CTDNews December'97. http://www.cdc.gov/niosh/whatsnew.html

4. Maeda K, Horiguchi S, Hosokava N. History of the studies on occupational cervicobrachial disorder in Japan and remaining problems. J Human Ergol 1982;11:17-29.

5. Awerbuch M. Different concepts of musculoskeletal pain. Ann Rheum Dis 1995;54:859-860.

6. Baerger AR. Cumulative trauma disorders. Curso Anual da Academia Americana de Neurologia. Washington, 1995.

7. Diário Oficial da União. 19 agosto 1998. Seção 27:27-38.

8. Hales TR, Bernard BP. Epidemiology of work-related musculoskeletal disorders. Orthop Clin N Am 1996;27:679-709.

9. Millender LH, Tromanhauser SG, Gaynor S. A team approach to reduce disability in work-related disorders. Orthop Clin N Am 1996;27:669-6770.

10. Pêgo CAA, Carneiro CM, Almeida EHR. História da LER no Brasil. In Oliveira CR (Ed). Manual prático de LER. Belo Horizonte: Health, 1997;55-62.

11. Melhorn JM. Cumulative trauma disorders and repetitive strain injuries: the future. Clin Orthop 1998;351:107-126.

12. Vender MI, Height A, Kasdam ML, Louisviille, Truppa KL. Upper extremity disorders: a literature review to determine work-relatdness. J Hand Surg 1995;20A:534-541. 
13. Hadler NM. Cumulative trauma disorders. J Occup Med 1990;32:38-41.

14. Hadler NM. Repetitive upper extremity motions in the workplace are not hazardous. J Hand Surg 1997;22A:19-29.

15. McDermott FT. Repetition strain injury. Med J Aust 1986;144:196-200.

16. Kasdan ML, Millender LH. Occupational soft-tissue and tendon disorders. Orthop Clin N Am 1996;27:795-803.

17. Cohen ML, Arroyo JF, Champion GD, Browne CD. In search of the pathogenesis of refractory cervicobrachial syndrome: a deconstruction of the RSI phenomenon. Med J Aust 1992;156:432-436.

18. Yunus MB. Towards a model of pathophysiology of fibromyalgia: aberrant central pain mechanisms with peripheral modulation. J Rheumatol 1992;19:846-850.

19. Shorter E. Somatization and chronic pain in historic perspective. Clin Orthop 1997;336:52-60.

20. Peltier LF. The classics. John Eric Erichsen (1818-1896). Clin Orthop 1997;336:4-10.

21. Assunção AA. Sistema músculo-esquelético: lesões por esforços repetitivos. In: Mendes R (ed) Patologia do trabalho. Rio de Janeiro: Ateneu 1995:173-212.

22. Couto HA, Nicoletti SJ, Lech O. Como gerenciar a questão das L.E.R./D.O.R.T. Belo Horizonte: Ergo,1998.

23. Portenoy RK, Kanner RM. Definition and asssesment of pain. In: Portenoy RK, Kanner RM. Pain management: theory and practice. Philadelphia FA Davis, 1996:3-18.

24. Miller MH, Topliss DJ. Chronic upper limb syndrome (repetitive strain injury) in the Australian workforce: a systematic cross sectional rheumatological study in 229 patients. J Rheumatol 1988;15:1705-1712.

25. Weintraub MI. Chronic pain in litigation: what is the relationship? Neurol Clin 1995;13:341-349.

26. Cunningham LS, Kelsey JL. Epidemiology of musculoskeletal impairments and associated disability. Am J Public Health 1984;74:574-579.

27. Kroenke K, Price RX. Symptoms in the community: prevalence, classification, and psychiatric comorbity. Arch Intern Med 1993;153:2474-2480.

28. Barsky AJ, Borus JF. Somatization and medicalization in the era of managed care. JAMA 1995;274:1931-1934.

29. Waddel G. A new clinical model for the treatment of low back pain. Spine 1987;12:632-644.

30. Loeser JD, Sullivan M. Doctors, diagnosis, and disability: a disastrous diversion. Clin Orthop 1997;336:61-66.

31. Louis DS. Presidential address: are we yet? J Hand Surg 1998;23A:191-195.

32. Kennedy WA. Permanent disability: the legacy of tort litigation. Clin Orthop 1997;336:67-71

33. Halleck SL. Perils of being a plaintiff: impressions of a forensic psychiatrist. Clin Orthop 1997;336:72-78.

34. Bellamy R. Editorial comment. Clin Orthop 1997;336:2-3.

35. Guest GH, Drummond PD. Effect of compensation on emotional state and disability in chronic back pain. Pain 1992;48:125-130.

36. Wright GD. The failure of the "RSI" concept. Med J Aust 1987;147:233-236.

37. Bell DS. "Repetition strain injury": an iatrogenic epidemic of simulated injury. Med J Aust 1989;151:280-284.

38. Cleland LG. "RSI": a model of social iatrogenesis. Med J Aust 1987;147:236-239.

39. Lister GH. Ergonomic disorders. J Hand Surg 1995;20A:353.

40. Weiland AJ. Repetitive strain injuries and cumulative trauma disorders. J Hand Surg 1996;21 A:337.

41. Higgs PE, Edwards D, Martin DS, Weeks PM. Carpal tunnel surgery outcomes in workers: effects of workers compensation status. J Hand Surg 1995;20A:354-360. 